Check for updates

Cite this: Mater. Adv., 2022, 3, 1539

Received 9th October 2021 Accepted 5th December 2021

DOI: 10.1039/d1ma00937k

rsc.li/materials-advances

\title{
Tailoring co-doping of cobalt and nitrogen in a fullerene-based carbon composite and its effect on the supercapacitive performance $\uparrow$
}

\author{
Bohong Jiang, $\ddagger^{\mathrm{a}}$ Guangpu Zhang, $\ddagger^{\mathrm{b}}$ Qin Tang, ${ }^{\mathrm{c}}$ Fancang Meng, ${ }^{\mathrm{a}}$ Dechun Zhou, ${ }^{\mathrm{a}}$ \\ Wenli Zhao, ${ }^{a}$ Wei Jiang (iD *b and Qingmin Ji (iD *a
}

\begin{abstract}
Fullerene-based carbons have attracted great attention in applications of energy storage and conversion due to their unique properties and tunable architectures. However, fullerene's poor long-range conductivity limits their application performance for supercapacitors. Therefore, developing active fullerenebased carbons with high capacitances is expected. In this work, mesoporous carbon composites with various doping amounts of cobalt $(\mathrm{CO})$ and nitrogen $(\mathrm{N})$ were fabricated via manipulation of fullerene self-assembly with a cobalt tetramethoxy phenylporphyrin (CoTMPP) and pyrolysis. The confined state of COTMPPs within the fullerene superstructures facilitates the fixation of $\mathrm{Co}$ and $\mathrm{N}$ during the carbonation and leads to a highly homogeneous distribution state within fullerene-based carbon composites. When used as electrodes for supercapacitors, the doped carbon composite showed significantly improved electrochemical performance. The specific capacitance could be nearly ten times higher than that of the fullerene carbons without doping and they have excellent cyclic stability. The work presents new insight into controllable functional doping of carbon materials. It may also further promote the development of fullerene superstructures for advanced electrochemical applications.
\end{abstract}

\section{Introduction}

Unlike other kinds of carbon materials, fullerene could be used as building blocks to assemble into multi-dimensional superstructures with various morphologies and transform into stable mesoporous carbon materials after thermal treatments. ${ }^{1-6}$ Due to their unique properties and tunable architectures at the molecular level, these fullerene-based carbons have attracted great attention for application in solar cells, energy storage and conversion..$^{7-9}$ However, when used as electrode materials for supercapacitors, the specific capacitance of the fullerene-based carbons was still relatively low. Therefore, the search for an

\footnotetext{
${ }^{a}$ Herbert Gleiter Institute for Nanoscience, School of Materials Science and Engineering, Nanjing University of Science \& Technology, 200 Xiaolingwei, Nanjing, 210094, China. E-mail: jiqingmin@njust.edu.cn

${ }^{b}$ National Special Superfine Powder Engineering Technology Research Center, Nanjing University of Science and Technology, 200 Xiaolingwei, Nanjing, 210094, China. E-mail: superfine_jw@126.com

${ }^{c}$ School of Chemistry and Chemical Engineering, Yancheng Institute of Technology, No. 1 Mid. Xiwang Avenue, Yancheng, China

$\dagger$ Electronic supplementary information (ESI) available: SEM and TEM images, FTIR spectra, Raman spectra, XPS spectra, nitrogen isotherms and CV curves of fullerene superstructures and related fullerene-based carbons. See DOI: 10.1039/ d1ma00937k

\$ B. J and G. Z contributed equally to this work.
}

active fullerene-based supercapacitor with improved performance is still needed.

Doping heteroatoms in the structure is one of the best solutions to overcome the shortcomings of fullerene's poor long-range conductivity. ${ }^{10-12}$ It may also improve the structural features of the fullerene superstructures for electrochemical applications. ${ }^{13,14}$ Almost all the species, metals or non-metals could be doped in fullerenes. Particularly, metal doping may effectively improve the electronic properties of fullerene-derived carbons. ${ }^{15-17}$ The doped metals could form a binary electron acceptor-donor system and provide more active sites in the structures. ${ }^{18}$

Various strategies have been applied for the metal doping of fullerene superstructures. For example, Peng et al. fabricated three-dimensional cross-type Fe-doped fullerene structures by self-assembly of ferrocene-modified fullerene and achieved enhanced electrochemical performance. ${ }^{19}$ Saianand et al. introduced copper into fullerene superstructures by a hard template and used them as effective catalysts for the oxygen reduction reaction (ORR).$^{20}$ We also successfully prepared fullerene carbon materials with enhanced supercapacitive properties by regulating the self-assembled structures of ferrocene-modified fullerenes in our previous work. ${ }^{21}$ However, these studies still cannot control the doping ratio of metals. The relationship between the metal doping content and application performance of fullerene-derived carbons is thus unclear. 


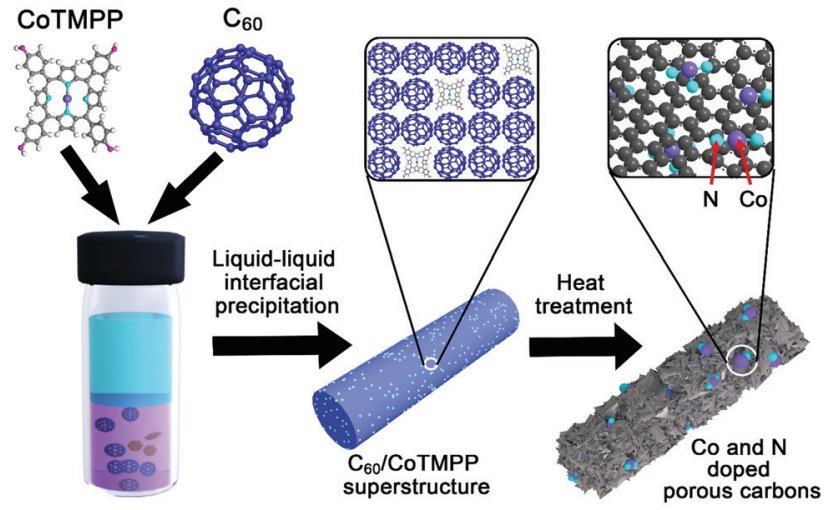

Fig. 1 Scheme for the preparation of $\mathrm{Co}$ and $\mathrm{N}$ doped carbon composites by manipulating $\mathrm{C}_{60}$ assembly with CoTMPP and pyrolysis.

Herein, we fabricated cobalt (Co) and nitrogen (N) doped mesoporous carbon composites based on the liquid-liquid interfacial precipitation (LLIP) process of $\mathrm{C}_{60}$ fullerenes with a cobalt tetramethoxy phenylporphyrin (CoTMPP) and pyrolysis. By manipulating the mixing ratios of $\mathrm{C}_{60}$ and CoTMPP, we obtained various porous carbon materials with controllable doping amounts of Co and N (totally $0.30-1.52 \%$ ) (Fig. 1). Co, a transition metal, has excellent energy storage capability for supercapacitors. But unfavorable aggregation may easily occur during the doping process or their usage. ${ }^{22}$ The confined state of CoTMPP within $\mathrm{C}_{60}$ crystalline structures could prevent Co agglomeration in the carbon structure and successfully dope functional Co and $\mathrm{N}$ simultaneously. With the homogenous distribution of Co and $\mathrm{N}$, the resultant mesoporous carbon composites exhibit excellent energy storage performance, the specific capacitance value of which could be about ten times higher than that of the fullerene carbons without doping and also well maintained $99.5 \%$ specific capacitance at least after 5000 cycles.

\section{Experimental part}

\section{The assembly process of fullerene superstructures}

$\mathrm{C}_{60} \mathrm{~S}$ are dissolved in toluene (about $2.5 \mathrm{mg} \mathrm{mL}^{-1}$ ) by sonication for 1 hour. The undissolved $\mathrm{C}_{60} \mathrm{~S}$ in the toluene solution are removed by filtration. The self-assembly of fullerenes is based on the liquid-liquid interfacial precipitation (LLIP) process. For details, $4 \mathrm{ml} \mathrm{C}_{60}$ solution is placed in a glass bottle $(15 \mathrm{~mL})$, and $8 \mathrm{~mL}$ IPA is slowly added on the top of the solution to form an interface. The mixture solution is left undisturbed for 5 minutes and then stored at room temperature for 12 hours after shaking. The sediment from the process is collected by centrifugation. In the $\mathrm{C}_{60}$ CoTMPP assembly process, $\mathrm{C}_{60}$ and CoTMPP with different mixing ratios $(5: 1,10: 1,20: 1)$ are dissolved in toluene by sonication, and then similar procedures mentioned above are followed. The $\mathrm{C}_{60}$ CoTMPP crystals obtained from mixing ratios of $5: 1,10: 1$, and $20: 1$ are named $\mathrm{C}_{60}$ CoTMPP-0.2, $\mathrm{C}_{60}$ CoTMPP-0.1 and $\mathrm{C}_{60}$ CoTMPP-0.05, respectively.

\section{Formation of mesoporous carbons from fullerene} superstructures

The collected precipitate from the LLIP process is dried under vacuum. The dry samples are then heated to $900{ }^{\circ} \mathrm{C}$ with a heating speed of $10^{\circ} \mathrm{C} \mathrm{min}^{-1}$ and kept for 2 hours at $900{ }^{\circ} \mathrm{C}$ in a tubular pyrolysis furnace under a constant nitrogen flow $\left(120 \mathrm{~cm}^{3} \mathrm{~min}^{-1}\right)$. The carbonized $\mathrm{C}_{60}$ CoTMPP crystals from $\mathrm{C}_{60}$ CoTMPP-0.2, $\mathrm{C}_{60}$ CoTMPP-0.1 and $\mathrm{C}_{60}$ CoTMPP-0.05 are named $\mathrm{C}_{60}$ CoTMPP-0.2_900, $\mathrm{C}_{60}$ CoTMPP-0.1_900 and $\mathrm{C}_{60}$ CoTMPP0.05_900, respectively.

\section{Electrochemical measurements}

The electrochemical performance is measured in a threeelectrode system in $1 \mathrm{M} \mathrm{H}_{2} \mathrm{SO}_{4}$ aqueous electrolyte. A glassy carbon electrode is used as the working electrode, with a $\mathrm{Ag} / \mathrm{AgCl}$ electrode as the reference electrode and Pt wire as the counter electrode. For the preparation of the working electrode, one drop of the IPA-water suspension of the porous carbon samples $\left(5 \mu \mathrm{L}, 5 \mathrm{mg} \mathrm{mL}^{-1}\right)$ is spread on the surface of the glassy carbon electrode and dry at room temperature. $2.5 \mu \mathrm{L}$ Nafion solution $(0.05 \%)$ is dropped on the glassy carbon electrode before the measurement. The specific capacitance $\left(C_{\mathrm{s}}\right)$ is calculated from the cyclic voltammograms (CV) the galvanostatic charge/discharge (CD) curves according to the following equations:

$$
\begin{gathered}
C_{\mathrm{s}}(\text { weight })=\mathrm{Q} /(2 \Delta E \cdot \mathrm{v} \cdot \mathrm{m}) \\
\text { or } C_{\mathrm{s}}(\text { area })=\mathrm{Q} /(2 \Delta E \cdot \mathrm{v} \cdot \mathrm{A}) \\
C_{\mathrm{s}}=I /(m \cdot \Delta E / \Delta t)
\end{gathered}
$$

in which $Q$ is the area encircled by $\mathrm{CV}, I$ is the voltammetric current or the constant current for charge-discharge, $\Delta E$ is the potential range, $v$ is the scan rate, $A$ is the surface area of the active material, $m$ is the mass of the active material, and $\Delta t$ is the discharge time, respectively.

\section{Characterization}

Field emission scanning electron microscopy (FE-SEM) is performed at $15 \mathrm{kV}$ on a FEI Quanta 250FEG. Transmission electron microscopy (TEM) is performed by using a Tecnai G220 at $200 \mathrm{kV}$. Nitrogen sorption measurements are conducted on powder samples at $77 \mathrm{~K}$ using an Autosorb-1 surface area and pore size analyzer (Gemini VII 2390). X-Ray diffraction (XRD) patterns are measured using a Bruker-AXS D8 Advance diffractometer. Raman spectra are recorded on a Raman scattering spectrometer (Renishaw-invia) using excitation radiation at $514 \mathrm{~nm}$ from an $\mathrm{Ar}^{+}$ion laser and at a power of $10 \mathrm{~mW}$. Fourier transform infrared (FTIR) spectra are obtained using a FTIR spectrometer Nicolet S10 (Thermo Fisher). The Co contents in the carbon samples are determined by inductively coupled plasma optical emission spectroscopy (ICP-OES) using Agilent 5110. 


\section{Results and discussion}

Fullerene superstructures from the mixture of $\mathrm{C}_{60}$ and CoTMPP

According to the solubility of $\mathrm{C}_{60}$ in solvents, $\mathrm{C}_{60} \mathrm{~S}$ may selfassemble into crystalline superstructures at the interface of good and bad solvents. ${ }^{23}$ Therefore, various solvent types could affect the packing of $\mathrm{C}_{60} \mathrm{~S}$ and lead to different morphologies of $\mathrm{C}_{60}$ superstructures. As the driving force of the fullerene assembly is mainly based on $\pi-\pi$ interactions, other $\pi$-molecules may easily intercalate into the $\mathrm{C}_{60} \mathrm{~s}$ superstructures from the co-assembly. ${ }^{8}$ In the system with CoTMPP, a metalloporphyrin molecule, as its metal ion center could coordinate with carbon atoms in fullerene, ${ }^{24,25}$ it may thus further promote the insertion into $\mathrm{C}_{60}$ superstructures.

In this work, we use toluene (PhMe)-isopropyl alcohol (IPA) as the solvent system to carry out the self-assembly of $\mathrm{C}_{60} \mathrm{~S}$ based on the LLIP process. Without mixing CoTMPP, the assembly of $\mathrm{C}_{60} \mathrm{~S}$ at the toluene-IPA interface leads to the formation of nanorods. As shown in Fig. S1 (ESI $\dagger$ ), the nanorods are $\sim 400 \mathrm{~nm}$ in diameter, $\sim 10 \mu \mathrm{m}$ in length and possess smooth surfaces. The co-assembly with CoTMPP alters the packing of $\mathrm{C}_{60} \mathrm{~S}$ and leads to the formation of $\mathrm{C}_{60}$ CoTMPPs with completely different morphologies (Fig. 2 and Table S1, ESI $\dagger$ ). $\mathrm{C}_{60}$ CoTMPP-0.2 shows rod morphology with polyprism structures (Fig. 2a). Its length is $\sim 2.5 \mu \mathrm{m}$ and its diameter is $\sim 1 \mu \mathrm{m}$. $\mathrm{C}_{60}$ CoTMPP-0.1 seems to possess microparticles with lamellar structures (about $\sim 1.9 \mu \mathrm{m}$ in diameter) and a rough surface (Fig. 2b). While for $\mathrm{C}_{60}$ CoTMPP-0.05 with the lowest mixing amount, similar rod morphology like the nanorods from pure $\mathrm{C}_{60} \mathrm{~S}$ is obtained (Fig. 2c), but it shows shorter lengths $(\sim 2.3 \mu \mathrm{m})$ and larger diameters $(\sim 1.2 \mu \mathrm{m})$. We suggest that the influence of the CoTMPP amount on the morphologies
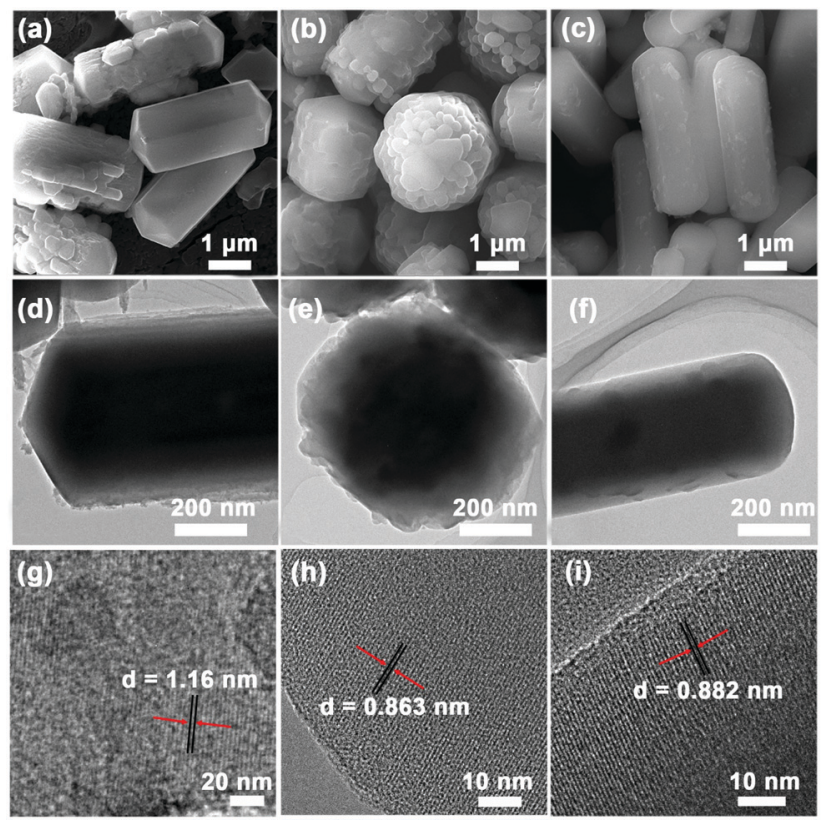

Fig. 2 SEM and TEM images of ( $a, d$ and g) $C_{60}$ CoTMPP-0.2; ( $b$, e and $h$ ) $\mathrm{C}_{60}$ CoTMPP-0.1; and ( $\mathrm{c}, \mathrm{f}$ and i) $\mathrm{C}_{60}$ CoTMPP-0.05. of $\mathrm{C}_{60}$ CoTMPP superstructures should be caused by the strong packing inclination between CoTMPPs. CoTMPPs can form flaky crystals in the solvent mixture of PhMe-IPA (Fig. S2, ESI $\dagger$ ). This aggregation inclination of CoTMPPs may change their insertion state within $\mathrm{C}_{60} \mathrm{~S}$ and might also interfere with the packing of $\mathrm{C}_{60} \mathrm{~s}$ during the co-assembly process. It thus leads to distinct structural features of the $\mathrm{C}_{60}$ CoTMPP superstructures. It should be mentioned that even higher content of CoTMPP is possible to assemble with $\mathrm{C}_{60} \mathrm{~s}$. For example, crystalline nanosheets of $\mathrm{C}_{60} / \mathrm{CoTMPP}$ can be formed at a mixing ratio of $1: 1$. However, the $\mathrm{C}_{60} /$ CoTMPP hybrid structure with mixing ratios higher than 5:1 may cause serious fusion of Co components and destroy the morphology during the following heat treatment. As the resultant blocks can hardly be used for further applications, we thus focus on the $\mathrm{C}_{60}$ /CoTMPP superstructures with the mixing ratio lower than $5: 1$.

The elemental mapping analyses indicate the homogenous distributions of $\mathrm{Co}, \mathrm{N}$, and $\mathrm{C}$ elements across the microstructures for all $\mathrm{C}_{60}$ CoTMPP superstructures (Fig. S3, ESI $\dagger$ ). HRTEM observations prove the changes of $\mathrm{C}_{60} \mathrm{~S}$ packing after the intercalation of CoTMPPs (Fig. 2g-i). The nanorods from bare $\mathrm{C}_{60} \mathrm{~s}\left(\mathrm{C}_{60}\right.$-rod) show regular lattices of $1.21 \mathrm{~nm}$ and $0.927 \mathrm{~nm}$, which correspond to the (110) and (101) planes (Fig. S4, ESI $\dagger$ ). The lattice spacing of $\mathrm{C}_{60}$ CoTMPP superstructures is inclined to shrink with the increase of the CoTMPP amount. As shown in Fig. $2 \mathrm{~g}, \mathrm{C}_{60}$ CoTMPP-0.2 shows a lattice spacing of $1.16 \mathrm{~nm}$ for the (110) plane, while the spacing of $\mathrm{C}_{60}$ CoTMPP-0.1 and $\mathrm{C}_{60}$ CoTMPP-0.05 turns to be $0.863 \mathrm{~nm}$ and $0.882 \mathrm{~nm}$ for the (101) plane, respectively.

The detailed crystalline structures of $\mathrm{C}_{60}$ CoTMPPs are analyzed by the X-ray diffraction (XRD) technique (Fig. 3). Similar to $\mathrm{C}_{60}$ nanorods without CoTMPP, the XRD patterns of $\mathrm{C}_{60}$ CoTMPPs also show the characteristic peaks of the HCP phase. However, with the presence of CoTMPP, a new diffraction peak at $6.2^{\circ}$, which should arise from the packing of CoTMPPs, appeared. The diffraction peak for the (110) plane (around 7.4 ${ }^{\circ}$ ) also shifts to a little higher degree for $\mathrm{C}_{60}$ CoTMPPs, which is consistent with the TEM observations. The intercalation of CoTMPPs within $\mathrm{C}_{60} \mathrm{~S}$ might strengthen the interactions between molecules and lead to the spacing shrinkage of $\mathrm{C}_{60} \mathrm{~S}$.

To understand the molecular interactions between $\mathrm{C}_{60}$ and CoTMPP, FTIR spectra of pure $\mathrm{C}_{60}$ rods, CoTMPP, and $\mathrm{C}_{60}$ CoTMPPs were measured (Fig. S5, ESI $\dagger$ ). The peaks around $550 \mathrm{~cm}^{-1}, 1185 \mathrm{~cm}^{-1}$ and $1430 \mathrm{~cm}^{-1}$ for $\mathrm{C}_{60}$ nanorods and $\mathrm{C}_{60}$ CoTMPPs can be attributed to the ring stretching and deformation vibrations of $\mathrm{C}_{60} \mathrm{~s}^{26}$ The characteristic peaks of CoTMPP at 750-900 $\mathrm{cm}^{-1}(\rho$-substituted phenyl groups and $\mathrm{N}-\mathrm{H}$ bending), $1510 \mathrm{~cm}^{-1}$ (C-C bonds in the pyrrole ring), $1254 \mathrm{~cm}^{-1}$ (C-N stretching vibration), and $1000 \mathrm{~cm}^{-1}$ (breathing modes of the pyrrole ring) are found to shift to lower wavenumbers for $\mathrm{C}_{60}$ CoTMPPs. ${ }^{27}$ This implies the interactions between the porphyrin moieties and $\mathrm{C}_{60} \mathrm{~S}$ in the $\mathrm{C}_{60}$ CoTMPPs.

\section{Mesoporous carbon from $\mathrm{C}_{60} /$ CoTMPP crystals}

As solvent molecules exist within the fullerene superstructures from the LLIP assembly process, carbonization of fullerene 


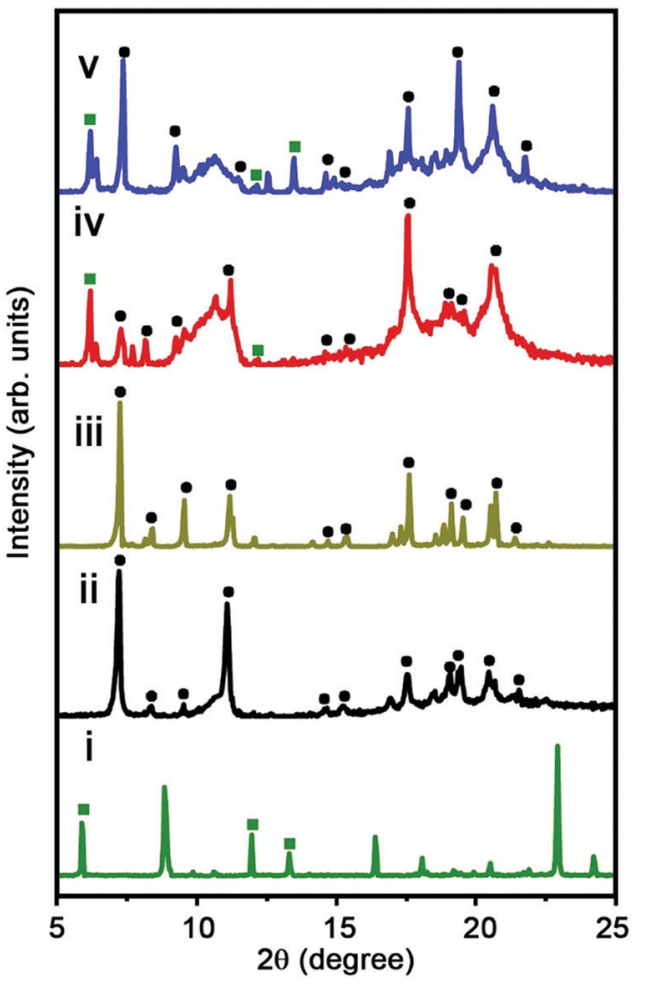

Fig. 3 XRD patterns of $\mathrm{C}_{60}$ CoTMPP structures. (i) $\mathrm{C}_{60}$ CoTMPP_0.2, (ii) $\mathrm{C}_{60}$ CoTMPP_0.1, (iii) $\mathrm{C}_{60}$ CoTMPP_0.05, (iv) $\mathrm{C}_{60}$-rods, and (v) CoTMPPs.

superstructures may induce the formation of meso- or micropores in the carbon structures, which is beneficial for their applications for energy storage. In this work, $\mathrm{C}_{60}$ CoTMPP crystals were carbonized through heat treatment at $900{ }^{\circ} \mathrm{C}$ under $\mathrm{N}_{2}$ flow.

The Raman spectra of the resultant $\mathrm{C}_{60}$ CoTMPP_900s exhibit two strong bands around 1360 and $1580 \mathrm{~cm}^{-1}$, corresponding to the $\mathrm{D}$ band from defect-containing or disordered graphitic carbon and the $\mathrm{G}$ band from the in-plane vibration of $\mathrm{sp}^{2}$ carbons (Fig. 4a). The typical peaks from $\mathrm{C}_{60}$ (two $\mathrm{A}_{\mathrm{g}}$ bands and six $\mathrm{H}_{\mathrm{g}}$ bands), which are observed in Raman spectra of $\mathrm{C}_{60}$ CoTMPPs, disappeared (Fig. S6, ESI $\dagger$ ). This indicates the successful structural transformation to carbon materials after the heat treatment (Fig. 4a). The intensity ratios of the $\mathrm{D}$ band and $\mathrm{G}$ band $\left(I_{\mathrm{D}} / I_{\mathrm{G}}\right)$ for $\mathrm{C}_{60} \_900$ (without CoTMPP), $\mathrm{C}_{60}$ CoTMPP0.05_900, C 60 CoTMPP-0.1_900 and C 60 $_{60}$ CoTMPP-0.2_900 are $0.76,1.09,0.92$ and 1.18 . This result suggests that the intercalation of CoTMPPs in the fullerene superstructures may induce the formation of more defects in the carbon structures. But the orders of $I_{\mathrm{D}} / I_{\mathrm{G}}$ for $\mathrm{C}_{60}$ CoTMPP_900s are not exactly the same as the CoTMPP amount in $\mathrm{C}_{60}$ CoTMPPs. This implies that the intercalation state of CoTMPP might also influence the transforming structures of carbons. In $\mathrm{C}_{60}$ CoTMPP_900s, the $A_{1 \mathrm{~g}}$ vibration mode $\left(690 \mathrm{~cm}^{-1}\right)$ of Co components appears and its intensity is increased with the additional CoTMPP amount in $\mathrm{C}_{60}$ CoTMPPs. ${ }^{28,29}$ This suggests the consistence of the Co doping amount of $\mathrm{C}_{60}$ CoTMPP_900s with the intercalated CoTMPPs in $\mathrm{C}_{60}$ CoTMPPs.

The XRD patterns of $\mathrm{C}_{60}$ CoTMPP_900s also indicate that the characteristic diffraction peaks of $\mathrm{C}_{60}$ CoTMPP disappeared
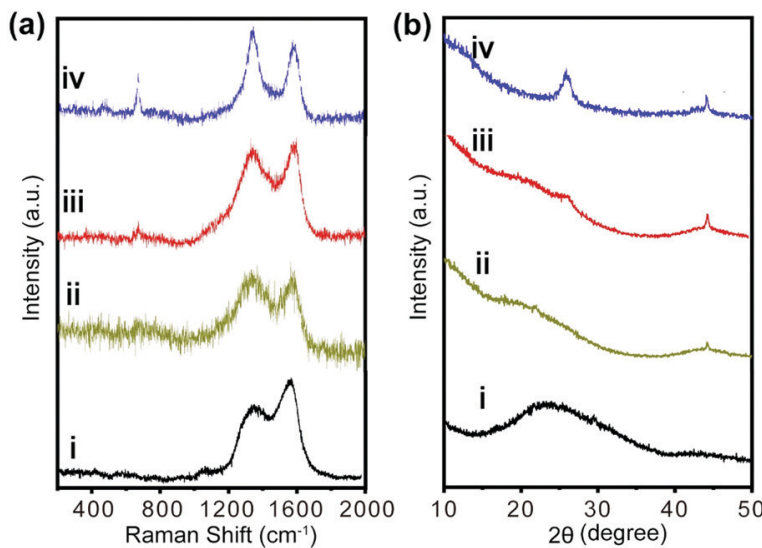

Fig. 4 (a) Raman spectra and (b) XRD patterns of $\mathrm{C}_{60}-900$ s and C60CoTMPP_900s. (i) $C_{60}$ 900s (ii) $C_{60}$ CoTMPP-0.05_900, (iii) $C_{60}$ CoTMPP0.1_900, and (iv) C60 CoTMPP-0.2_900.

after carbonation (Fig. 4b). Unlike the carbonized $\mathrm{C}_{60} 900$ (without doping) with only a wide peak in the range of $20-30^{\circ}$, two additional diffraction peaks appeared at $25.8^{\circ}$ and $44.2^{\circ}$ for $\mathrm{C}_{60}$ CoTMPP_900s. The diffraction at $25.8^{\circ}$ is ascribed to the (002) plane of graphite, ${ }^{30}$ which suggests that the existence of CoTMPP might promote the stacking of graphene sheets during the structural transformation of fullerenes into carbons. While the diffraction at $44.2^{\circ}$ should arise from the planes of cobalt nitride and cobalt oxide, ${ }^{31,32}$ which can be attributed to the (111) plane of $\mathrm{CoN}_{4}$ (JCPDS No. 41-0943) and the (400) plane of $\mathrm{Co}_{3} \mathrm{O}_{4}$ (JCPDS No. 42-1467) (Fig. S7, ESI $\dagger$ ). Its peak intensity is shown to increase with the mixing amount of CoTMPP in $\mathrm{C}_{60}$ CoTMPPs, indicating again varied doping amounts of Co and $\mathrm{N}$ in $\mathrm{C}_{60}$ CoTMPP_900s.

The TEM observations directly indicate the formation of the porous matrix of $\mathrm{C}_{60}$ CoTMPP_900s from the dense crystalline nature of $\mathrm{C}_{60}$ CoTMPPs (Fig. S8, ESI $\dagger$ and Fig. 5). Compared with various $\mathrm{C}_{60}$ CoTMPP_900s, we can find that $\mathrm{C}_{60}$ CoTMPP0.1_900 has a much looser networked structure, which means more pore spaces and larger exposure surfaces for active sites. The elemental mapping analyses based on TEM prove the existence of Co, N, and $\mathrm{C}$ elements (Fig. 5). This also reveals the maintenance of the dispersion state of Co and $\mathrm{N}$ after the high-temperature heat treatment. With different doping amounts, $\mathrm{C}_{60}$ CoTMPP_900s possess varied Co distribution states in the structure (Fig. S8, ESI $\dagger$ ). C ${ }_{60}$ CoTMPP-0.01_900 shows tiny nanoparticles of Co components with relatively scattered distributions. We can also observe tiny nanoparticles in the structure of $\mathrm{C}_{60}$ CoTMPP-0.1_900, but it has much more dense distributions. While for $\mathrm{C}_{60}$ CoTMPP-0.2_900, nanoparticles can be hardly found, and metal components seem to aggregate as blocks in the structure.

To understand the molecular transformation during the pyrolysis, we use thermogravimetric analysis (TGA) to gain information (Fig. S9, ESI $\dagger$ ). The thermograms of $\mathrm{C}_{60}$ CoTMPPs show a small weight loss of $5-8 \%$ below $150{ }^{\circ} \mathrm{C}$, which should be attributed to the removal of solvent molecules within the superstructures. The weak mass loss that occurred between 450 


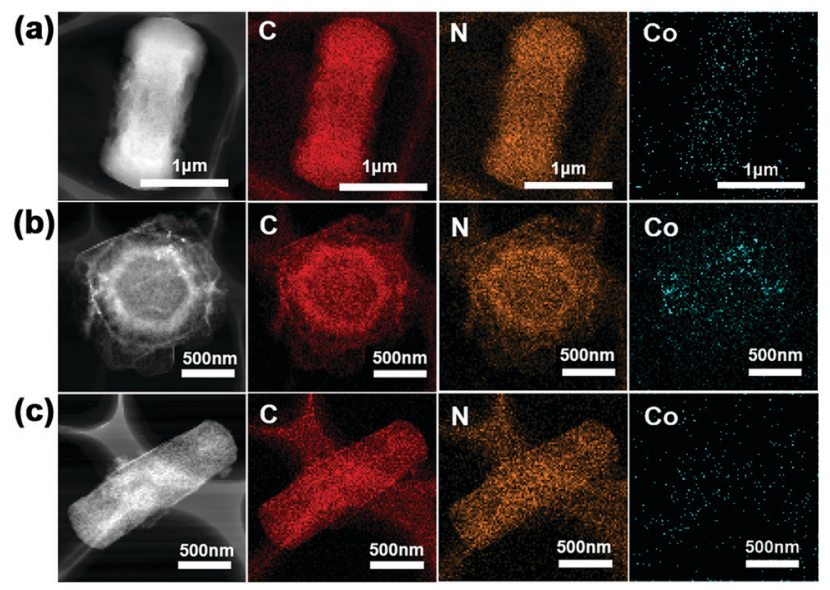

Fig. 5 STEM images and the corresponding elemental mapping images of C60 CoTMPP_900s. (a) C60 CoTMPP-0.2_900, (b) C 60 CoTMPP-0.1_900, and (c) C60 CoTMPP-0.05_900.

and $600{ }^{\circ} \mathrm{C}$ is related to the gradual decomposition of CoTMPP. A significant mass loss at a temperature higher than $700{ }^{\circ} \mathrm{C}$ is observed, which should be associated with molecular changes from $\mathrm{C}_{60} \mathrm{~s} . \mathrm{C}_{60} \mathrm{~S}$ are transferred into carbon networks or decomposed by the oxygen within the structures. Comparing the weight loss ratios of $\mathrm{C}_{60}$ CoTMPPs and $\mathrm{C}_{60}$-rod, we can find that the presence of CoTMPPs in the $\mathrm{C}_{60}$ superstructures may effectively restrain the decomposition of $\mathrm{C}_{60} \mathrm{~S}$ during the pyrolysis. The oxygen within the structure might prefer to combine with Co. This leads to the formation of more oxidized Co and lower decomposition of $\mathrm{C}_{60} \mathrm{~s}$ for $\mathrm{C}_{60}$ CoTMPPs with a large mixing amount of CoTMPP.

The chemical states of $\mathrm{Co}$ and $\mathrm{N}$ in $\mathrm{C}_{60}$ CoTMPP_900s are further analyzed based on XPS measurement (Fig. 6 and Fig. S10, ESI $\dagger$ ). Fig. 6a shows the Co 2p spectrum in the binding energy range from 770 to $810 \mathrm{eV}$ by the Gaussian method. It contains split spin-orbit $2 \mathrm{p}_{3 / 2}(778-785 \mathrm{eV})$ and $2 \mathrm{p}_{1 / 2}(793-$ $798 \mathrm{eV})$ regions. The spectrum is fitted into two states, whose peaks at 779 and $795 \mathrm{eV}$ should belong to $\mathrm{Co}^{3+}(\mathrm{Co}-\mathrm{O})$; peaks at 782 and $797 \mathrm{eV}$ are attributed to $\mathrm{Co}^{2+}\left(\mathrm{Co}-\mathrm{N}_{x}\right)$ with satellite peaks at 786 and $805 \mathrm{eV}^{33,34}$ The $\mathrm{N} 1 \mathrm{~s}$ spectra are deconvoluted into five peaks, which can be assigned to primary pyridine $\mathrm{N}(398.5 \mathrm{eV})$, metal $N(399.2 \mathrm{eV})$, pyrrole $N(400.2 \mathrm{eV})$, graphite $N(401.5 \mathrm{eV})$, and oxidized $N(404.5 \mathrm{eV})$ (Fig. 6b). ${ }^{35,36}$ The C $1 \mathrm{~s}$ spectrum shows the existence of a $\mathrm{C}=\mathrm{N}$ bond $(285.8 \mathrm{eV})$ with $\mathrm{C}=\mathrm{C}(284.4 \mathrm{eV})$ and a $\mathrm{C}-\mathrm{O}$ bond $(289.2 \mathrm{eV})$ (Fig. 6c). ${ }^{37}$ These results indicate that the doped $\mathrm{Co}$ and $\mathrm{N}$ atoms may form $\mathrm{Co}-\mathrm{N}$ and $\mathrm{Co}-\mathrm{O}$ in the carbon network of the fullerene-derived carbons.

According to the relative area of each component peak in XPS spectra, the proportions of different Co states in $\mathrm{C}_{60}$ CoTMPP_900s are compared (Table S2, ESI $\dagger$ ). The $\mathrm{Co}-\mathrm{N}: \mathrm{Co}-\mathrm{O}$ ratio is 1.52 ( $\mathrm{C}_{60}$ CoTMPP-0.05_900), 3.66 ( $\mathrm{C}_{60}$ CoTMPP-0.1_900), and 0.5 ( $\left.\mathrm{C}_{60} \mathrm{CoTMPP}-0.2 \_900\right)$, respectively. These results indicate that the formation of $\mathrm{Co}-\mathrm{N}$ becomes greatly restrained in the carbonization of $\mathrm{C}_{60}$ CoTMPPs when a large amount of CoTMPP is involved. Since CoTMPP in large amounts tends to aggregate themselves during the co-assembly with $\mathrm{C}_{60} \mathrm{~s}$, the densely packed state of CoTMPPs in the superstructure and the oxygen in CoTMPPs may promote the oxidation of Co during carbonization and lead to the formation of less Co-N. ICP measurement was further employed to confirm the Co content in $\mathrm{C}_{60}$ CoTMPP_900s (Table S3, ESI $\dagger$ ). The result indicates that the mass fraction of the Co element is $1.52 \%$ for $\mathrm{C}_{60}$ CoTMPP0.2_900, $0.71 \%$ for $\mathrm{C}_{60} \mathrm{CoTMPP}-0.1 \_900$, and $0.30 \%$ for $\mathrm{C}_{60}$ CoTMPP-0.05_900, respectively. In comparison of Co ratios in $\mathrm{C}_{60}$ CoTMPP (before carbonation), which are $1.26 \%$ $\left(\mathrm{C}_{60}\right.$ CoTMPP- 0.2$), \quad 0.57 \% \quad\left(\mathrm{C}_{60}\right.$ CoTMPP- 0.1$)$ and $0.26 \%$ ( $\mathrm{C}_{60}$ CoTMPP-0.05), there is almost no loss of doped Co during the heating process. Compared with the theoretical content of Co in $\mathrm{C}_{60}$ CoTMPP (Table S3, ESI $\dagger$ ), there are also no big differences. These results demonstrate that we could precisely control the doping amount of $\mathrm{Co}$ in the fullerene carbon materials through this assembly process.

The doping influence on the porous structures of $\mathrm{C}_{60}$ CoTMPP_900s is analyzed based on nitrogen adsorption/ desorption isotherms (Fig. S11, ESI $\dagger$ ). Brunauer-Emmett-Teller (BET) and Barrett-Joyner-Halenda (BJH) methods are adapted to calculate the specific surface area and pore size distributions (Table S4, ESI $\dagger$ ). The isotherms of $\mathrm{C}_{60}$ CoTMPP_900s are shown to be of type IV with a H3 hysteresis loop. This indicates the existence of mesopores and a small part of micropores in $\mathrm{C}_{60}$ CoTMPP_900s. C 60 CoTMPP-0.1_900 has the highest BET surface area of about $496 \mathrm{~m}^{2} \mathrm{~g}^{-1}$, while those of $\mathrm{C}_{60}$ CoTMPP0.2_900 and C 60 CoTMPP-0.05_900 are $365 \mathrm{~m}^{2} \mathrm{~g}^{-1}$ and $446 \mathrm{~m}^{2} \mathrm{~g}^{-1}$, respectively. As the intercalation of CoTMPP in $\mathrm{C}_{60} \mathrm{~s}$ may bring more packing disorders in the structure, it might facilitate the (a)

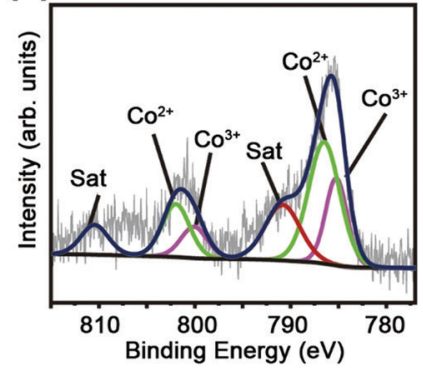

(b)

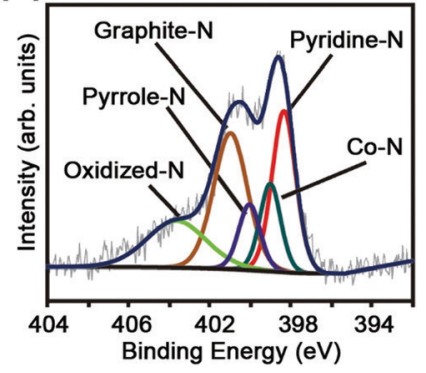

(c)

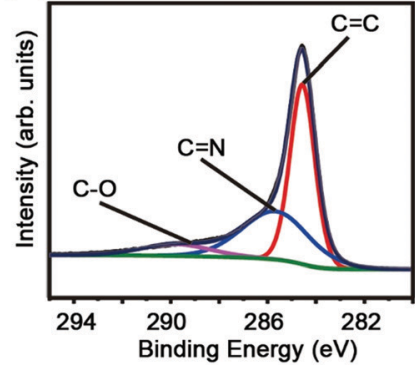

Fig. 6 XPS spectra of $C_{60}$ CoTMPP-0.1_900. (a) Co $2 p$ spectrum, (b) N 1s spectrum, and (c) C 1s spectrum. 
production of more pores from the decomposition during the heat treatment. This thus leads to a higher surface area of $\mathrm{C}_{60}$ CoTMPP_900s than the porous carbon from pure $\mathrm{C}_{60} \mathrm{~S}$ $\left(\mathrm{C}_{60} \_900\right)$, the surface area of which is $285 \mathrm{~m}^{2} \mathrm{~g}^{-1}$ (Fig. S12, ESI $\dagger$ ). However, when more CoTMPPs are involved, the presence of more CoTMPP aggregates and their effect on promoting the stacking of graphene sheets may diminish part of pores in the carbon structures, resulting in lower surface areas and also narrower distribution of pore size for $\mathrm{C}_{60}$ CoTMPP-0.2_900.

\section{Electrochemical performances of $\mathrm{C}_{60} / \mathrm{CoTMPP}$-900s}

The porous carbons derived from $\mathrm{C}_{60}$ CoTMPP_900s are applied as electrode materials for supercapacitors. Their electrochemical supercapacitive properties are measured based on cyclic voltammetry (CV) and galvanostatic charge-discharge cycles (GCD) by using a three-electrode configuration in $1 \mathrm{M} \mathrm{H}_{2} \mathrm{SO}_{4}$ aqueous electrolyte. $\mathrm{C}_{60}$ CoTMPP_900s are deposited at the surface of the glassy carbon electrode. SEM observation of the $\mathrm{C}_{60}$ CoTMPP_900 layers indicates their uniform coverage states on the electrode surface with porous nature accessible for electrolytes (Fig. S13, ESI $\dagger$ ). The CV curves of $\mathrm{C}_{60}$ CoTMPP_900s at $10 \mathrm{mV} \mathrm{s}^{-1}$ over the range of $0-0.8 \mathrm{~V}$ are shown in Fig. $7 \mathrm{a}$. All samples display a rectangular-like shape curve, which proves that $\mathrm{C}_{60}$ CoTMPP_900s could act like a typical doublelayer capacitor. In contrast to the low specific capacitance of $\mathrm{C}_{60 \_} 900$ without doping $\left(32.5 \mathrm{~F} \mathrm{~g}^{-1}\right.$ at $10 \mathrm{mV} \mathrm{s}^{-1}$ and $46.9 \mathrm{~F} \mathrm{~g}^{-1}$ at $1 \mathrm{~A} \mathrm{~g}^{-1}$ ) (Fig. S14, ESI $\dagger$ ), ${ }^{21} \mathrm{C}_{60}$ CoTMPP_900s with Co and $\mathrm{N}$ doping all show enhanced capacitive property of fullerenebased carbons. $\mathrm{C}_{60}$ CoTMPP-0.1_900 possesses the highest specific capacitance of $296 \mathrm{~F} \mathrm{~g}^{-1}$ or $0.1 \mathrm{~F} \mathrm{~cm}^{-2}$. $\mathrm{C}_{60}$ CoTMPP0.05_900 and $\mathrm{C}_{60}$ CoTMPP-0.2_900 have a specific capacitance of $168 \mathrm{~F} \mathrm{~g}^{-1}\left(0.06 \mathrm{~F} \mathrm{~cm}^{-2}\right)$ and $55 \mathrm{~F} \mathrm{~g}^{-1}\left(0.02 \mathrm{~F} \mathrm{~cm}^{-2}\right)$, respectively. That is to say, the capacitance order of $\mathrm{C}_{60}$ CoTMPP_900s is
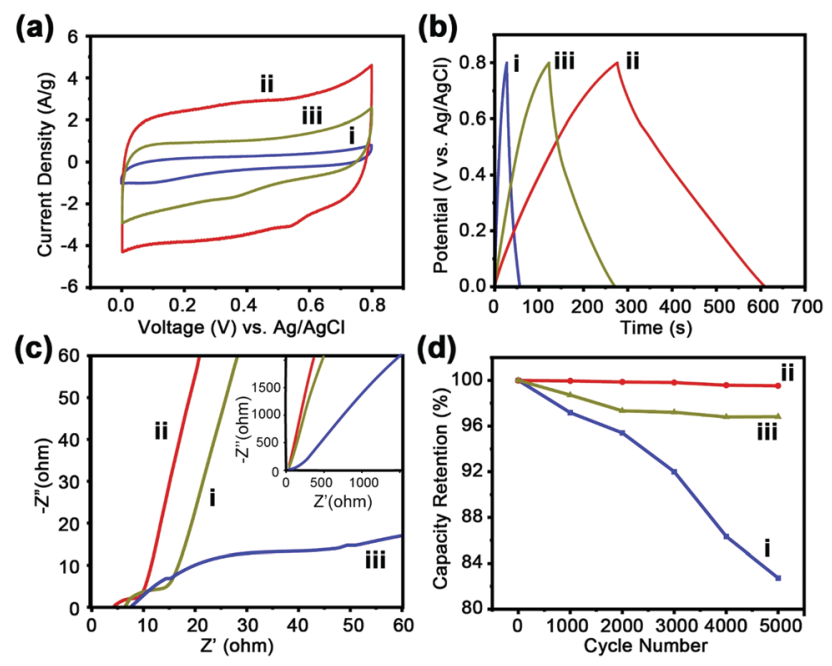

Fig. 7 (a) CV curves of $C_{60}$ CoTMPP_900s at a scan rate of $10 \mathrm{mV} \mathrm{s}^{-1}$. (b) CD curves of $C_{60}$ CoTMPP_900s at a current density of $1 \mathrm{~A} \mathrm{~g}^{-1}$; (c) Nyquist plots of $\mathrm{C}_{60}$ CoTMPP_900s; and (d) cycling stability test of C60CoTMPP_900s. (i) C 60 CoTMPP_0.2-900, (ii) C60 CoTMPP_0.1-900, and (iii) $\mathrm{C}_{60}$ CoTMPP_0.05-900.
$\mathrm{C}_{60}$ CoTMPP-0.1_900 $>\mathrm{C}_{60}$ CoTMPP-0.2_900 $>\mathrm{C}_{60}$ CoTMPP0.05_900. This order is consistent with that of the surface area of $\mathrm{C}_{60}$ CoTMPP_900s and Co-N content in the carbons. This means that both structural and chemical factors may affect the performance. The surface area of the electrode is demonstrated as one major factor for supercapacitor performance. ${ }^{38}$ It is related to the ion diffusion ability in the carbon electrode and the formation of an ion-electron double layer. The double-layer capacitance is known to be directly proportional to the surface area. ${ }^{39}$ But for this system, the capacitance difference of $\mathrm{C}_{60}$ CoTMPP_900s is much larger than that of their BET surface areas. This implies that the doping state of Co-N should bring great influence on their effective surface area for ion diffusion and conversion, which leads to a large difference in the electrochemical performance. However, the distinct effects from the porous structure and doping state cannot be evaluated separately. The assembly structures of fullerenes are sensitive to the assembly conditions. Small changes in the type and volume of solvents or additives may alter the structural features of the fullerene superstructures. ${ }^{23,40}$ Therefore, the intercalation of functional molecules within the $\mathrm{C}_{60}$ s superstructures will inevitably change the assembled morphologies. The advantage of tunable architectures for fullerene assemblies always accompanies the functions.

The GCD curves of $\mathrm{C}_{60}$ CoTMPP_900s are all triangular shapes, which also indicates a typical double-layer capacitor of the samples. The longer discharge time of $\mathrm{C}_{60}$ CoTMPP0.1_900 means a higher specific capacitance of $416.31 \mathrm{~F} \mathrm{~g}^{-1}$ at $1 \mathrm{~A} \mathrm{~g}^{-1}$ (Fig. 7b). Compared with other reported fullerenederived carbon materials (Table S5, ESI $\dagger$ ), the performance of $\mathrm{C}_{60}$ CoTMPP-0.1_900 could exceed those of most of the reported fullerene carbon materials.

To further investigate the mechanism of charge storage for supercapacitors, electrochemical impedance spectroscopy (EIS) is performed. The Nyquist plots of $\mathrm{C}_{60}$ CoTMPP_900s reveal good capacitive behaviors (Fig. 7c), which possess a semicircle in the high-frequency area and inclined linear plot at low frequencies. The width of the semicircle at high frequencies can determine charge transfer resistance $\left(R_{\mathrm{ct}}\right)$, which is associated with the charge transfer across the electrode-electrolyte interface. C $_{60}$ CoTMPP-0.1_900 displays the shortest diameter of the semicircle, which means the lowest $R_{\mathrm{ct}}$. This indicates more effective charge transfer and better capacitive contribution in $\mathrm{C}_{60}$ CoTMPP-0.1_900. The slope inclination in the low-frequency area is related to internal resistance $\left(R_{\mathrm{S}}\right)$. As $\mathrm{C}_{60}$ CoTMPP-0.1_900 exhibits the highest inclination degree, a higher electrical conductivity of $\mathrm{C}_{60}$ CoTMPP-0.1_900 is suggested. The calculated $R_{\mathrm{ct}}$ values for C ${ }_{60}$ CoTMPP-0.05_900, C $_{60}$ CoTMPP-0.1_900, and $\mathrm{C}_{60}$ CoTMPP-0.2_900 are 11.2, 5.6, and $45.4 \Omega$, and the $R_{\mathrm{S}}$ values are 6.2, 4.6, and 8.2 $\Omega$, respectively. $\mathrm{C}_{60}$ CoTMPP-0.2_900 shows the highest $R_{\mathrm{ct}}$ and $R_{\mathrm{S}}$ values, which suggests that besides the Co doping amount, the doping state and structural features may also have a large influence on the electron transfer in the carbon composites.

From the above results, it is observed that the content of Co-N in the carbon composites plays the main role in 
improving the electrochemical performance. $\mathrm{C}_{60}$ CoTMPP-0.1_900 possesses unique morphology and highest content of $\mathrm{Co}-\mathrm{N}$, and thus exhibits better capacitance than $\mathrm{C}_{60}$ CoTMPP-0.05_900 and $\mathrm{C}_{60}$ CoTMPP-0.2_900. Although $\mathrm{C}_{60}$ CoTMPP-0.2_900 has the highest Co doping amount, more doped Co in the carbon structure exists as the Co-O state with the least content of $\mathrm{Co}-\mathrm{N}$, which brings an adverse effect on the conductivity of the carbon composite. The doping influence on the structural features also affects the electrochemical performance. The doping ratio of CoTMPP for $\mathrm{C}_{60}$ CoTMPP-0.1 completely changes the inclination of forming the rod morphology. The homogeneous distribution of CoTMPP in $\mathrm{C}_{60}$ CoTMPP-0.1 also facilitates the formation of $\mathrm{Co}-\mathrm{N}$ and the transformation of more porous structures during the carbonation process. With less doping of CoTMPP, the assembled structure largely maintains the features of the $\mathrm{C}_{60}$ superstructures without doping and shows limited influence on the formation of pores during the carbonation. While for $\mathrm{C}_{60}$ CoTMPP- 0.2 with large doping of CoTMPP, CoTMPPs are dispersed in the superstructure as molecular aggregates and may more easily induce the formation of $\mathrm{Co}-\mathrm{O}$ and dense packing of graphite carbons during the heat treatment. These factors make $\mathrm{C}_{60}$ CoTMPP-0.2_900 exhibit the worst performance. It should be noted that besides the doping content in $\mathrm{C}_{60}$ CoTMPP_900s, the existence of graphitic carbons is also important for electrochemical performance. Based on the TGA result, $\mathrm{C}_{60} \mathrm{~S}$ will not begin carbon transformation at a temperature lower than $700{ }^{\circ} \mathrm{C}$. This means that no graphitic carbons formed for the carbonized $\mathrm{C}_{60}$ CoTMPPs by $700{ }^{\circ} \mathrm{C}$. The resultant carbons also show poor electrochemical performance (Fig. S15, ESI $\dagger$ ), in which $\mathrm{C}_{60}$ CoTMPP-0.1_700 only has a specific capacitance of $35 \mathrm{~F} \mathrm{~g}^{-1}$, similar to fullerene-carbons without doping.

Considering the best electrochemical performance of $\mathrm{C}_{60}$ CoTMPP-0.1, we further evaluate its electrochemical stability. Fig. S16 (ESI $\dagger$ ) shows the CV curves of $\mathrm{C}_{60}$ CoTMPP-0.1_900 at different scan rates from 10 to $100 \mathrm{mV} \mathrm{s}^{-1}$. All curves at different scan rates display quasi-rectangular shape, indicating the good maintenance of double-layer capacitor behavior as well as good rate capability. The capacitance retention is also excellent, which is shown to keep $>99 \%$ of the initial capacitance after 5000 GCD cycles (Fig. 7d). In contrast, $\mathrm{C}_{60}$ CoTMPP0.05 900 could maintain about $97 \%$ of the capacitance, but $\mathrm{C}_{60}$ CoTMPP-0.2_900 shows a big decrease with the cycles. The worse electrochemical stability for $\mathrm{C}_{60}$ CoTMPP-0.2_900 should be due to the existence of more $\mathrm{Co}-\mathrm{O}$ in the carbon composite, since cobalt oxides have disadvantages of poor electrical conductivity, easy polarization, and volumetric expansion during the charge and discharge processes. ${ }^{41,42}$ Therefore, this result further proves that the control of the CoTMPP intercalation state in $\mathrm{C}_{60}$ structures is essential to both the porous feature and the doping states of Co in the carbon composites.

\section{Conclusions}

In summary, we successfully manipulated the intercalation of CoTMPP in the $\mathrm{C}_{60}$ self-assembled structure through the LLIP process and fabricated $\mathrm{C}_{60}$ composite crystals with various microscopic morphologies. After carbonization, the CoTMPP confined in the $\mathrm{C}_{60}$ crystals transformed into active Co- $\mathrm{N}$ in the carbon structures. The content of Co-N is shown to be not only directly related to the mixing ratio of CoTMPP in $\mathrm{C}_{60}$ crystals but also the distribution state in the superstructures. The presence of $\mathrm{Co}-\mathrm{N}$ in the porous carbon composites improves the electrochemical properties greatly. The resultant carbon composite showed an enhanced specific capacitance of 416.31 $\mathrm{F} \mathrm{g}^{-1}$ at $1 \mathrm{~A} \mathrm{~g}^{-1}$, which is almost ten times higher than that of the $\mathrm{C}_{60}$ carbons without doping, and could almost show no activity loss after at least 5000 cycles. This work brings new insight into controllable functional doping of carbon materials by fullerene interfacial self-assembly. This may also further promote the development of fullerene superstructures for advanced electrochemical applications.

\section{Conflicts of interest}

There are no conflicts to declare.

\section{Acknowledgements}

This work has been financially supported by Instrument \& Equipment Open Funding of Nanjing University of Science and Technology, by the National Natural Science Foundation of China No. 21875108 and by the Fundamental Research Funds for the Central Universities (No. 30921013106).

\section{Notes and references}

1 M. R. Benzigar, S. Joseph, H. Ilbeygi, D. H. Park, S. Sarkar, G. Chandra, S. Umapathy, S. Srinivasan, S. N. Talapaneni and A. Vinu, Angew. Chem., Int. Ed., 2020, 57, 569-573.

2 T. Xu, W. Shen, W. Huang and X. Lu, Mater. Today Nano, 2020, 11, 100081.

3 L. K. Shrestha, Q. Ji, T. Mori, K. Miyazawa, Y. Yamauchi, J. P. Hill and K. Ariga, Chem. - Asian. J., 2013, 8, 1662-1679.

4 F. Lu, E. A. Neal and T. Nakanishi, Acc. Chem. Res., 2019, 52, 1834-1843.

5 R. G. Shrestha, L. K. Shrestha, M. Abe and K. Ariga, J. Nanosci. Nanotechnol., 2015, 15, 2394-2399.

6 Q. Tang, P. Bairi, R. G. Shrestha, J. P. Hill, K. Ariga, H. Zeng, Q. Ji and L. K. Shrestha, ACS Appl. Mater. Interfaces, 2017, 9, 44458-44465.

7 Q. Tang, S. Maji, B. Jiang, J. Sun, W. Zhao, J. P. Hill, K. Ariga, H. Fuchs, Q. Ji and L. K. Shrestha, ACS Nano, 2019, 13, 14005-14012.

8 Q. Tang, S. Zhang, X. Liu, M. Sumita, S. Ishihara, H. Fuchs, Q. Ji, L. K. Shrestha and K. Ariga, Phys. Chem. Chem. Phys., 2017, 19, 29099-29105.

9 T. Anusha, K. S. Bhavani, J. S. Kumar and P. K. Brahman, Diamond Relat. Mater., 2020, 104, 107761.

10 P. Bairi, T. Tsuruoka, S. Acharya, Q. Ji, J. P. Hill, K. Ariga, Y. Yamauchi and L. K. Shrestha, Mater. Horiz., 2018, 5, 285-290. 
11 L. K. Shrestha, R. G. Shrestha, Y. Yamauchi, J. P. Hill, T. Nishimura, K. Miyazawa, T. Kawai, S. Okada, K. Wakabayashi and K. Ariga, Angew. Chem., Int. Ed., 2015, 127, 965-969.

12 P. Bairi, R. G. Shrestha, J. P. Hill, T. Nishimura, K. Ariga and L. K. Shrestha, J. Mater. Chem. A, 2016, 4, 13899-13906.

13 T. Wakahara, P. D’Angelo, K. Miyazawa, Y. Nemoto, O. Ito, N. Tanigaki, D. D. Bradley and T. D. Anthopoulos, J. Am. Chem. Soc., 2012, 134, 7204-7206.

14 T. Wakahara, M. Sathish, K. Miyazawa, C. Hu, Y. Tateyama, Y. Nemoto, T. Sasaki and O. Ito, J. Am. Chem. Soc., 2009, 131, 9940-9944.

15 S. Saha, P. Samanta, N. C. Murmu and T. Kuila, J. Energy Storage, 2018, 17, 181-202.

16 Z. Yu, L. Tetard, L. Zhai and J. Thomas, Energy Environ. Sci., 2015, 8, 702-730.

17 M. A. Lebedeva, T. W. Chamberlain and A. N. Khlobystov, Chem. Rev., 2015, 115, 11301-11351.

18 A. L. Balch and K. Winkler, Coord. Chem. Rev., 2021, 438, 213623.

19 Z. Peng, Y. Hu, J. Wang, S. Liu, C. Li, Q. Jiang, J. Lu, X. Zeng, P. Peng and F. F. Li, Adv. Energy Mater., 2019, 9, 1802928.

20 G. Saianand, A. I. Gopalan, J. C. Lee, C. Sathish, K. Gopalakrishnan, G. E. Unni, D. Shanbhag, V. D. Dasireddy, J. Yi and S. Xi, Small, 2020, 16, 1903937.

21 B. Jiang, Q. Tang, W. Zhao, J. Sun, R. An, T. Niu, H. Fuchs and Q. Ji, CrystEngComm, 2020, 22, 6287-6294.

22 S. J. Uke, V. P. Akhare, D. R. Bambole, A. B. Bodade and G. N. Chaudhari, Front. Mater., 2017, 4, 21.

23 J. Minato and K. Miyazawa, Carbon, 2005, 43, 2837-2841.

24 D. V. Konarev, S. S. Khasanov and R. N. Lyubovskaya, Coord. Chem. Rev., 2014, 262, 16-36.

25 D. M. Guldi, Chem. Soc. Rev., 2002, 31, 22-36.

26 G. Andrievsky, V. Klochkov, A. Bordyuh and G. Dovbeshko, Chem. Phys. Lett., 2002, 364, 8-17.

27 G. Zuo, X. Lu, Z. Xue, B. Lv, Y. Wang and J. Kang, Synth. React. Inorg. Met.-Org. Chem., 2006, 36, 589-594.
28 S. Bhattacharyya, B. Konkena, K. Jayaramulu, W. Schuhmann and T. K. Maji, J. Mater. Chem. A, 2017, 5, 13573-13580.

29 C. Liu, G. Bai, X. Tong, Y. Wang, B. Lv, N. Yang and X.-Y. Guo, Electrochem. Commun., 2019, 98, 87-91.

30 L. Fu, Y. Chen, S. Zhao, Z. Liu and R. Zhu, RSC Adv., 2016, 6, 19482-19491.

31 J. Sheng, L. Wang, L. Deng, M. Zhang, H. He, K. Zeng, F. Tang and Y.-N. Liu, ACS Appl. Mater. Interfaces, 2018, 10, 7191-7200.

32 Y. Wu, Q. Shi, Y. Li, Z. Lai, H. Yu, H. Wang and F. Peng, J. Mater. Chem. A, 2015, 3, 1142-1151.

33 S.-H. Cho, K. R. Yoon, K. Shin, J.-W. Jung, C. Kim, J. Y. Cheong, D.-Y. Youn, S. W. Song, G. Henkelman and I.-D. Kim, Chem. Mater., 2018, 30, 5941-5950.

34 K. Niu, B. Yang, J. Cui, J. Jin, X. Fu, Q. Zhao and J. Zhang, J. Power Sources, 2013, 243, 65-71.

35 J. M. Ziegelbauer, T. S. Olson, S. Pylypenko, F. Alamgir, C. Jaye, P. Atanassov and S. Mukerjee, J. Phys. Chem. C, 2008, 112, 8839-8849.

36 Y. Jiang, Y. Lu, X. Wang, Y. Bao, W. Chen and L. Niu, Nanoscale, 2014, 6, 15066-15072.

37 S. S. Park, S.-W. Chu, C. Xue, D. Zhao and C.-S. Ha, J. Mater. Chem., 2011, 21, 10801-10807.

38 E. J. Lee, L. Lee, M. A. Abbas and J. H. Bang, Phys. Chem. Chem. Phys., 2017, 19, 21140-21151.

39 E. Taer, A. Agustino, R. Farma, R. Taslim, Awitdrus, M. Paiszal, A. Ira, S. D. Yardi, Y. P. Sari, H. Yusra, S. Nurjanah, S. D. Hartati, Z. Aini and R. N. Setiadi, J. Phys.: Conf. Ser., 2018, 1116, 032040.

40 K. Ariga and L. K. Shrestha, Mater. Adv., 2021, 2, 582-597.

41 S. Wang, L. Li, Y. Shao, L. Zhang, Y. Li, Y. Wu and X. Hao, Adv. Mater., 2019, 31, 1806088.

42 D. Qiu, X. Ma, J. Zhang, B. Zhao and Z. Lin, Chem. Phys. Lett., 2018, 710, 188-192. 